\title{
An invariant in mouse running wheel behavior
}

GEORGE COLLIER AND ALAN I. LESHAER

RUTGERS UNIVERSITY

The running of mice in two different sized running wheels was observed. The number of wheel turns, the distance run, and an approximation of the work done were calculated. It was found that the number of tums and the distance run were greater in the small wheels than in the large wheels but that the amount of work done was constant.

In 1933 Skinner reviewed the characteristics of the running wheel, emphasizing the importance of the physical characteristics and uniformity of the wheel to the understanding of the phenomena of activity. More recently, Kavanau \& Brant (1965) have shown the effects of varying the stimulational properties of the wheel on activity levels.

While the majority of the research on running wheel activity has utilized revolutions per time period as the dependent variable and has tended to ignore or not to vary the physical characteristics of the wheel, there is no reason to believe that this is the most important parameter of running wheel behavior. Either gross measures, such as time spent running or work done, or fine measures of the distribution of running (Premack \& Schaeffer, 1962, 1963) may prove to be the more relevant dependent variables.

One approach to the question of what function running plays in the animal's economy is to ask which, if any, of these measures is invariant across physical parameters. For example, when torque varies do animals spend constant amounts of time running, run constant distances, or expend constant amounts of work?

The present study attempts to answer this question by varying wheel diameter and, therefore, torque. Number of wheel turns, distance run, and work expended were examined.

Subjects

The Ss were 24 male mice of the C57BL/6J strain. The mice were 45 days of age at the start of the experiment.

\section{Apparafus}

The apparatus consisted of 12 Wahmann activity wheels. Six wheels had a circumference of $1.117 \mathrm{~m}$ and were designated large wheels, and six wheels had a circumference of $\mathbf{. 5 5 6} \mathrm{m}$ and were designated small wheels.

\section{Procedure}

The experiment was performed in two replications. There were six Ss in each sized wheel in each replication. One $\mathrm{S}$ was lost in the small wheel group in the second replication. The number of revolutions was recorded every $24 \mathrm{hr}$. The amount of weight that had to be added to the rim of the wheel in order to turn it 1/4 turn was measured for each wheel. The average weight that had to be added to the small wheels was $5.01 \mathrm{gm}$, and the average weight that had to be added to the large wheels was $6.70 \mathrm{gm}$. This measure only yields an estimate of the work done when the animal is running at a constant speed. The work done in accelerating and decelerating the wheel is neglected.

\section{Results}

The results are presented in Fig. 1 which shows the average wheel turns; distance run, and work expended for the two sized wheels.

An analysis of variance revealed that the number of revolutions per day and the distance run were significantly different $(F=27.13, \mathrm{df}=1 / 10, p<.001$; $\mathrm{F}=284.46, \mathrm{df}=1 / 10, \mathrm{p}<.001$ ) between the small wheels and the large wheels. There was no significant difference between groups on the work measure $(F=.003$, $\mathrm{df}=1 / 10, p>.05)$. There was, however, a significant interaction of wheel size by days $(F=3.85, d f=10 / 10$, $\mathrm{p}<.01)$. Figure 2 presents the averages of blocks of four days of the work measure. The significant interaction is attributable to the fact that small wheel animals did little running at first.

\section{Discussion}

These results indicate, as Skinner (1933) pointed out, that variations of the physical parameters of the running wheel affect the conventional measures of activity such as number of revolutions and distance run. However, when activity is examined from the point of view of an estimate of the work done, the differences due to varying these parameters do not appear to be significant.

If, as the present experiment indicates, work done
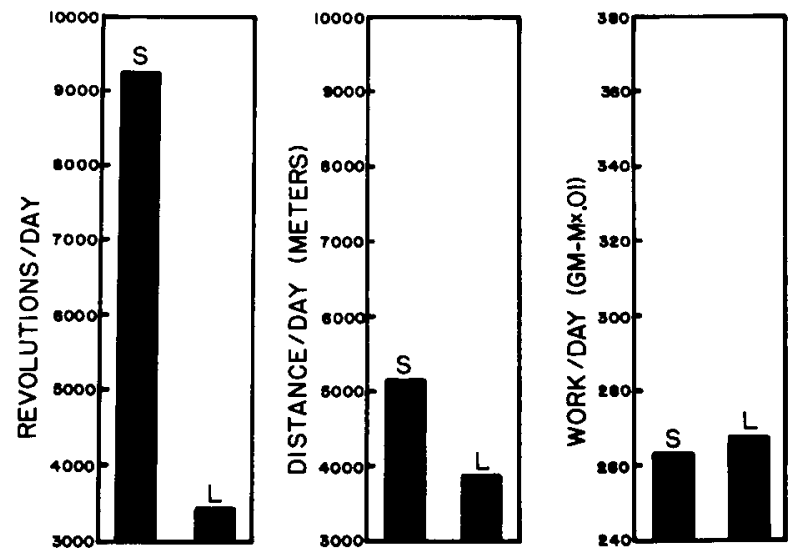

Fig. 1. Mean revolutions per day, distance run per day, and work expended per day. 


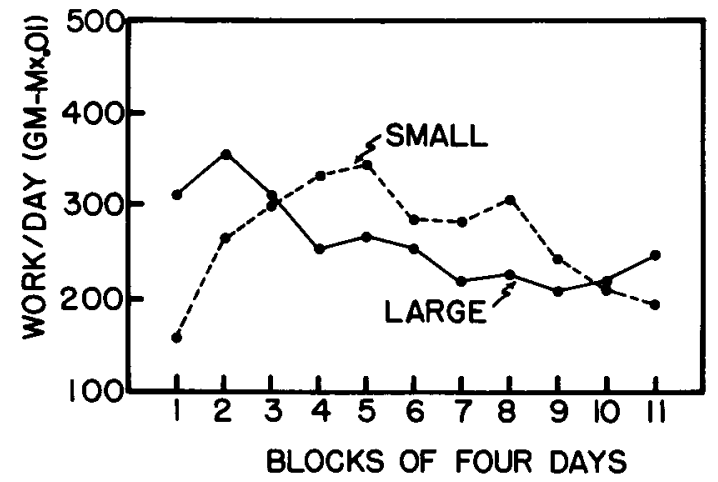

Fig. 2. Means of blocks of four days on the work per day measure.

is the relevant variable in wheel running, it is suggested that the role played by spontaneous running activity in the economy of the animal may be quite different from that usually suggested. For example, work may serve some function in the regulation of physiological parameters within the organism such as body weight and composition (Collier, Squibb, \& Jackson, 1965), or energy utilization.

\section{References}

Collier, G. H., Squibb, R. L., \& Jackson, J. Activity as a function of diet: I. Spontaneous activity. Psychon. Sci., 1965, 3, 173-174.

Kavanau, J. L., \& Brant, D. H. Wheel running preferences of Peromyscus. Nature, 1965, 208, 597-598.

Premack, D., \& Schaeffer, R. W. Distributional properties of operant level locomotion in the rat. J. exp. Anal. Behav., 1962, 5, 89-95.

Premack, D., \& Schaeffer, R. W. Some parameters affecting the distributional properties of operant level running in rats. J. exp. Anal. Behav., 1963, 6, 473-475.

Skinner, B. F. The measurement of "spontaneous activity." $J$ gen. Psychol., 1933, 9, 3-23.

\section{Note}

1. This work was supported by Grant HD-00941 from the National Institute of Mental Health, Bethesda, Maryland. 